Pointing out further that without more scientists and more scientific research the material future of the free world could not be assured and enlarged, Mr. Menzies also referred to the danger here of confusing ends with means. Whether scientific advance means human salvation or a new and complicated form of technological slavery depends on our character, our broad intelligence and our wise and understanding judgment. We must be ready to meet aggression with purpose as well as vigour, but our social policies and particularly our educational policies must be so devised as to encourage sanity and responsibility, and discover blundering accident. Psychologically, the true answer to the threat of war must be found in the improvement of the nature of man himself. The true end to be served is the enlargement of the human mind and spirit. We need more scientists, but also more scholars; more scholarly scientists; more scientific scholars; more historians and philosophers and poets. If science is truly to serve the cause of civilization it will be because the people who use the advances of science have grown to use them in a civilized way. Not all the most brilliant successes in laboratories and factories and fields would make a nation great in the eye of history if it had failed to enthrone the human spirit and to set about it knowledge, and justice, and patience, and understanding.

\title{
RADIO RESEARCH, 1957
}

$\mathrm{W}$ HILE research work devoted to various aspects of radio wave propagation is vital and should continue, it is recommended by the chairman of the Radio Research Board in his annual report* that the research programme of the Department of Scientific and Industrial Research Radio Research Station at Slough during the next five years should be broadened in scope, to ensure that experience is gained and progress made with other important topics. So far as possible, new fields of research should bear directly on practical applications, and examples include molecular amplifiers and oscillators, and the design and properties of microwave aerials. The radio transmissions from artificial Earth satellites, orbiting so that the source is sometimes within and sometimes above the ionosphere, already have provided a valuable new tool for examining ionospheric propagation, and frequency and directional measurements on the first two U.S.S.R. satellites were made at Slough. More accurate position data for the satellites are awaited before a full analysis of the results obtained is possible.

The work of the Radio Research Station is described in detail in the report of the Director, special emphasis having been given to items directly connected with the International Geophysical Year. In addition to the ionospheric observatories at Inverness, Port Stanley (Falkland Islands), Singapore and Slough, equipment designed or built at the Radio Research Station has been in operation at Halley Bay (Antarctica), Ibadan (Nigeria) and Port Lockroy (Grahamland). The Station has also been designated one of the four World Data Centres for the collection of all International Geophysical Year ionospheric data, the others being at Boulder (Colorado), Moscow and Tokyo. Data from about one hundred stations are sent directly to Slough, while those from some two hundred other stations arrive through the other three Centres.

Routine measurements over the current sunspot maximum period have yielded the highest monthly mean values of $F 2$ critical frequency ever recorded over twenty-six years. This experience suggests that in considering the allocation of appropriate frequencies for short-distance radio communication, a frequency of $60 \mathrm{Mc} . / \mathrm{s}$. may be taken as the upper limit ever likely to be used in normal $F$-region

* Department of Scientiflc and Industrial Research, Radio Research 1957: The Report of the Radio Research Board and the Report of the Director of Radio Research. Pp. iv $+43+4$ plates. (London : H.M. Stationery Office.) $3 s .6 d$, net. propagation. Work has continued on the selection of a suitable ionospheric index of solar activity, primarily as an aid to forecasting propagation conditions. A preliminary investigation suggests that it might be possible to produce a permanent set of charts which would give the critical frequency at any point in the world for any phase of the sunspot cycle (defined in terms of the ionospheric index of solar activity), and which ultimately should render many of the current routine ionospheric measurements unnecessary.

Work on oblique-incidence radio propagation in the high-frequency and very high-frequency bands has continued. An investigation is being made into a possibility that commercial use may be made of the observed lateral deviations of the propagation direction from the great circle path for frequencies of the order of $20 \mathrm{Mc} / \mathrm{s}$. when the latter mode has faded out. This phenomenon is not fully understood, but is thought to be due to some form of ground scattering. The value of the plan-position-indicator 'back-scatter' technique in the investigation of propagation modes to long distances is now established, and experiments are being made to compare the field-strength for forward propagation on a frequency of $17 \mathrm{Mc}$./s. with that for scatter reception from the same range. Another field of investigation is the forward-scattering of very high-frequency signals in the $E$-region, and associated with this form of propagation are the strong momentary enhancements of signal which are attributed to reflexions from sporadic meteors.

Long-distance 'scatter links' for ultra high frequencies, by which communication is obtained through forward scatter in the troposphere, are also being investigated at the Radio Research Station. Experiments are in progress on frequencies of 53 , 1,370 and 3,500 Mc./s. used over different path. lengths, with the view of clarifying the problem of whether the propagation is maintained as a result of random fluctuations of refractive index caused by turbulence throughout the whole troposphere, or is due to variations of refractive index in relatively restricted layers of the troposphere. $\mathrm{As}$ an aid to this study, direct measurements of tropospheric refractive index have been initiated and have so fax yielded encouraging results. Work has continued on the measurement of atmospheric radio noise, and equipment has been developed for routine use during the International Geophysical Year for measuring 
the detailed features of the noise in the frequencyrange $15 \mathrm{kc} . / \mathrm{s} .-30 \mathrm{Mc} . / \mathrm{s}$. with tho view of elucidating the mechanism whereby individual lightning flashes give rise to noise at different frequencies.

Observations of the phase and amplitude characteristics of very low-frequency waves $(10-20 \mathrm{kc} / \mathrm{s}$. reflected from the ionosphere are also described in "Radio Research 1957". The experimental work, which bears directly on the application of such waves for navigational aids over long distances, is being supplemented by theoretical work on the propagation of very low-frequency waves.

In addition to the work on radio propagation over a wide frequency-range, the Department is engaged on the development of radio-frequency power measuring standards, and research into semi-conductors and magnetic and dielectric materials. Work on germanium has been superseded by that on silicon filaments and commercial transistors, with particular reference to performance at very high radio-frequencies. The magnetic properties of a wide range of ferrites and other metal oxides and their applications to microwave measurements are being investigated.

Some of the work described in the report is undertaken, under contract with the Department, at various universities. A list of papers published during 1957 is given as an appendix. GeOFFrey M. Brow

\section{ECOLOGY OF SOIL FUNGI}

\begin{abstract}
HE growth, activities and interrelationships of fungi in soil provided the basis for a symposium on "The Ecology of Soil Fungi" held at the University of Liverpool during August 19-2l. The meeting, attended by ninety scientists from thirteen countries, was divided into six sessions, which were presided over, respectively, by Prof. N. A. Burges (University of Liverpool), Dr. P. W. Brian (Imperial Chemical Industries, Welwyn), Dr. J. Harley (University of Oxford), Prof. J. Guillemat (École National d'Agronomique, Grignon), Prof. J. Ziemiecka (Institut Uprawy, Pulawy, Poland) and Dr. H. Katznelson (Canadian Department of Agriculture, Ottawa). Each session included a review of one aspect of the subject and four or five shorter papers : most of the twenty-eight papers presented were circulated before the symposium and this undoubtedly contributed greatly to the very lively discussions.
\end{abstract}

Review papers by Dr. J. H. Warcup (Waite Agricultura] Institute, Adelaide, read by Dr. Parkinson and J. S. Waid (Fisons, Levington) dealt, respectively, with the isolation and estimation of activity of fungi in soil and the effect of environmental conditions on fungal growth in soil. Synecological investigations which were afterwards discussed included: the fungi associated with pine litter and couch grass debris (Dr. D. Parkinson and B. Kendrick, University of Liverpool); the distribution of Chytrids in lake muds and soil (Dr. L. G. Willoughby, Fresh Water Biological Association, Ambleside); the microflora of sandy soils in the Sahara (Dr. J. Nicot, Natural History Museum, Paris); the fungal flora of tidal mud flats before and during colonization by Salicornia stricta (Dr. G. J. F. Pugh, University of Nottingham); the growth of fungi in forest and grassland soils (Dr. R. H. Thormton, Soil Bureau, Wellington, New Zealand, read by Dr. Parkinson); and the rhizosphere flora of Abies of different ages (Dr. R. Moreau, Ecole Nationale de Médecine et de Pharmacie, Besançon). During the course of these papers and the discussions, the need for a greater knowledge of the origin of fungal isolates was emphasized. The use of the soil dilution plate count method, a subject of some considerable debate, was ably defended by Prof. J. Montegut (École National de Horticulture, Versailles), and an account of the use of this method in studies of the effects of nitrogen, phosphorus and potassium on soil fungi was submitted by Profs. J. Guillemat and J. Montegut. Dr. E. H. Garrard
(Ontario Agricultural College) surveyed the detailed work on Streptomyces scabies at Guelph. Directobservation studies of Verticillium albo-atrum in soil and tomato roots were described by Dr. G. W. F. Sewell (East Malling Research Station), and Dr. H. Tribe (University of Cambridge; read by Dr. S. Hepple, National Institute of Agricultural Botany, Cambridge) discussed his observational work on the decomposition of buried cellulose film.

A review by Dr. Brian of the antagonistic and competitive mechanisms limiting survival and activity of fungi in soil was followed by an account of antagonism as the background in which fungi live (Dr. D. Park, University of Manchester), and a description by Dr. R. Barton (University of Manchester) of investigations of substrate colonization by Pythium mamillatum under different conditions. Drs. A. G. Winter, F. Schonbeck and H. Peuss (Botanische Abteilung Madans, Köln Merhiem) discussed biotic factors, with reference to 'hyphospheres' and mycorrhizæ, affecting the development of soil fungi. Soil fungistasis, which Dr. Brian also included in his survey, was the subject of a paper by Dr. C. G. Dobbs, who reviewed some methods of study developed at the University College of North Wales, Bangor. Drs. Dobbs and J. Bywater (Bangor) described a seasonal variation in fungistasis in certain soils, and Dr. R. M. Jackson (Rothamsted Experimental Station) discussed the effect of living roots on the germination of fungal spores in soil.

Prof. Burges, in his paper "Dynamic Equilibrium of Soil Populations", discussed the effects on the soil micropopulation of seasonal fluctuation in depositions of organic matter. The uses of radiocarbon in studies on cellulose and lignin breakdown were described by Dr. J. Mayandon and Prof. P. Simonart (University of Louvain), while problems associated with the isolation of humic acid and its utilization as a nutrient by fungi were the subjects of a paper by Prof. Burges and Miss P. M. Latter. Certain aspects of fungal physiology in relation to soil studies were reviewed by Dr. Harley, whose paper was followed by accounts of the use of physiological methods, relating to oxidative metabolism, in mycological studies (Dr. D. Boulter and H. M. Hurst, University of Liverpool) and a demonstration by Dr. M. E. K. Henderson (Macaulay Institute, Aberdeen) that a number of fungi are able to decompose molecules related to lignin. Prof. C. G. C. Chesters (University of Nottingham) reviewed prob- 